between anti-CarPA and $\triangle \mathrm{DAS} 28$ showed association only with $\triangle \mathrm{DAS} 28$ from baseline to M6 $(p=0.005)$. In this period, the positive patients showed less decrease of DAS28 than the negative patients. This was independent of all the variables mentioned above and of the initial DAS28. As a result of this association, $20.5 \%$ of the anti-CarPA positive patients reached remission at M6, in comparison with $34.6 \%$ of the negative patients. In contrast, $\triangle \mathrm{DAS} 28$ from M6 to M12 and from M12 to M24 were small and not associated with anti-CarPA

Conclusions: Anti-CarPA were associated with high disease activity at presentation and with less improvement in the first 6 months of follow-up in EA patients These results reinforce the possibility that anti-CarPA could be useful in the clinic as prognostic biomarkers.

Acknowledgements: Supported by grants PI14/01651 and RD16/0012/0014,/ $0011, / 0012$ of the Instituto de Salud Carlos III (Spain) that are partially financed by the ERDF

Disclosure of Interest: None declared

DOI: 10.1136/annrheumdis-2018-eular.4562

\section{SAT0085 RELATIONSHIP BETWEEN SERUM CALPROTECTIN, DISEASE ACTIVITY PARAMETERS AND THE 7-JOINT ULTRASOUND SCORE IN RHEUMATOID ARTHRITIS}

M. Torgutalp ${ }^{1}$, A.B. Kelesoglu Dincer ${ }^{1}$, E.M. Yayla ${ }^{1}$, E. Uslu Yurteri ${ }^{1}$, E.I. Okatan ${ }^{1}$, G.E. Aydemir Guloksuz', S. Serdar', U. Ebru', G. Kinikli', M.T. Turgay ${ }^{1}$, A. Ates ${ }^{1}$. ${ }^{1}$ Rheumatology, ${ }^{2}$ Microbiology, Ankara University Faculty of Medicine, Ankara, Turkey

Background: Calprotectin may be a sensitive biomarker of rheumatoid arthritis (RA) disease activity.

Objectives: In this study we aimed to investigate whether calprotectin is a better biomarker than known inflammation markers forpredicting clinical activity and ultrasound parameters in patients with RA.

Methods: A total of 80 RA patients were underwent to clinical (swollen joint count, tender jointcount, disease activity score-DAS28, simplified disease activity indexSDAI and clinical disease activity index-CDAI) and ultrasound (German US7) examination. Correlation ofclinical, laboratory and ultrasound measures wereanalyzed using Spearman'scorrelation coefficient. The RA patients were divided into two subgroups according to their DAS28-ESR (erythrocyte sedimentation rate) score; group 1 (DAS-28 $\leq 3.2$ remission and low activity), group 2 (DAS28 $>3.2$ moderate and high activity), respectively. Thirty healthy controls were simultaneously studied.

Results: The serum calprotectin levels of the RA patients were significantly higher than those of healthy controls $(96.3 \pm 45.9,54.7 \pm 50.0$, respectively; $p<0.001$ ). Distribution of age (years; $57.2 \pm 9.6,53.9 \pm 10.5$, respectively; $p=0.115$ ) and sex (female; $78.8 \%, 70 \%$, respectively, $p=0.336$ ) between these groups were similar. The clinical, laboratory and ultrasound characteristics of the patients are shown in table 1. The calprotectin levels were $74.8 \pm 45.5$ in group $1(n=37)$ and $114.7 \pm 37.9$ in group $2(n=43)(p<0.001)$. The association between calprotectin and scores of DAS28-ESR are shown in figure $1 \mathrm{~A}$. Serum calprotectin was significantly associated with DAS28-ESR, DAS28-CRP (C-reactive protein), SDAI, CDAI, ESR, CRP and US7 parameters. We also found a moderate to strong correlation of US7 score with DAS28-ESR, DAS28-CRP, SDAI,CDAI, CRP and ESR (table 2). The correlation between calprotectin and US7 is shown in figure 1B.

Abstract SAT0085 - Table 1. Baseline characteristics of patients with RA

\begin{tabular}{lccc}
\hline & $\begin{array}{c}\text { Group 1 } \\
(\mathrm{n}=37)\end{array}$ & $\begin{array}{c}\text { Group 2 } \\
(\mathrm{n}=43)\end{array}$ & $\mathrm{p}$ \\
\hline Female Sex, $\mathrm{n}(\%)$ & $30(81.1)$ & $33(76.7)$ & 0.64 \\
Age, years & $55.4 \pm 9.4$ & $58.8 \pm 9.6$ & 0.12 \\
Disease duration, & $13.2 \pm 9.1$ & $12.2 \pm 7.6$ & 0.61 \\
years & & & \\
Seropositivity, $\mathrm{n}(\%)$ & $24(64.9)$ & $28(65.1)$ & 0.98 \\
ESR, mm/hour & $14.2 \pm 7.2$ & $42 \pm 18.5$ & $<0.001$ \\
CRP, mg/dl & $8.2 \pm 11.8$ & $23 \pm 25.7$ & $\mathbf{0 . 0 0 2}$ \\
CDAl & $4.3 \pm 2.1$ & $11.4 \pm 6.9$ & $<0.001$ \\
SDAl & $12.4 \pm 11.9$ & $34.4 \pm 29.4$ & $<0.001$ \\
US7 total score & $4.9 \pm 4.8$ & $8.1 \pm 6.9$ & $\mathbf{0 . 0 2 1}$ \\
Calprotectin, $\mathrm{ng} / \mathrm{ml}$ & $74.8 \pm 45.5$ & $114.7 \pm 37.9$ & $<\mathbf{0 . 0 0 1}$ \\
\hline
\end{tabular}

Table.2 Spearman's rank correlation coefficients between calprotectin, US7 scores and other variables:

\begin{tabular}{|c|c|c|c|c|c|c|c|}
\hline & ESR & CRP & $\begin{array}{c}\text { DAS28- } \\
\text { ESR }\end{array}$ & $\begin{array}{c}\text { DAS28- } \\
\text { CRP }\end{array}$ & CDAI & SDAI & US7 \\
\hline Calprotectin & $0.361^{* * *}$ & $0.306^{* *}$ & $0.488^{* * *}$ & $0.495^{* * *}$ & $0.482^{* \star \star}$ & $0.429^{* \star \star}$ & $0.444^{\text {** }}$ \\
\hline ESR & & $0.494^{* * *}$ & $0.816^{* * *}$ & $0.561^{* \star *}$ & $0.467^{\star \star \star}$ & $0.554^{* \star *}$ & $0.247^{\star}$ \\
\hline CRP & & & $0.512^{* \star *}$ & $0.780^{* * *}$ & $0.408^{\star * *}$ & $0.923^{* * *}$ & $0.309^{* *}$ \\
\hline DAS28-ESR & & & & $0.828^{* * *}$ & $0.846^{* \star *}$ & $0.695^{\star * *}$ & $0.441^{* * *}$ \\
\hline DAS28-CRP & & & & & $0.856^{* * *}$ & $0.924^{* \star *}$ & $0.501^{\star \star \star *}$ \\
\hline
\end{tabular}

\begin{tabular}{|c|c|c|}
\hline CDAI & $0.670^{* * *}$ & $0.509^{* * *}$ \\
\hline SDAI & & $0.418^{* * *}$ \\
\hline
\end{tabular}
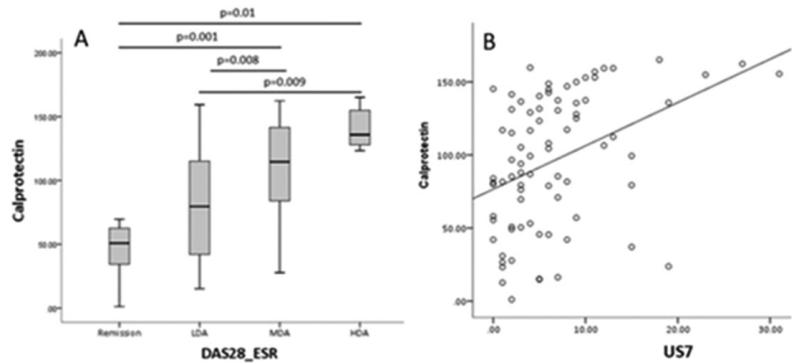

Abstract SAT0085 - Figure 1. A Box plotsbetween calprotectin and DAS28-ESR B. Correlation graph between calprotectin and US7 score

Conclusions: The results of our study support an additional role of calprotectin in assessing inflammatory activity in patients with RA.Therefore, the combination of serum calprotectinl evels and the US7 score could be a simple and practica assessment approach for detection of RA disease activity.

Disclosure of Interest: None declared

DOI: 10.1136/annrheumdis-2018-eular.4898

\section{SAT0086 EVALUATION OF DIAGNOSTIC PERFORMANCE OF MAGNETIC RESONANCE IMAGING (MRI) AND ULTRASOUND (US) TOWARD EARLY RHEUMATOID ARTHRITIS FROM NAGASAKI EARLY ARTHRITIS COHORT}

A. Takatani ${ }^{1}$, M. Tamai ${ }^{1}$, N. Ohki ${ }^{2}$, Y. Nakashima ${ }^{1}$, Y. Endo ${ }^{1}$, S. Tsuji ${ }^{1}$, T. Shimizu ${ }^{1}$ M. Umeda ${ }^{1}$, S. Fukui ${ }^{1}$, R. Sumiyoshi ${ }^{1}$, A. Nishino ${ }^{1}$, T. Koga ${ }^{1}$, S.-Y. Kawashiri ${ }^{1}$

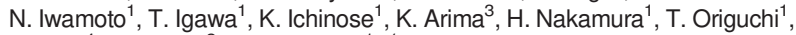
S. Sato ${ }^{4}$, M. Uetani ${ }^{2}$, A. Kawakami ${ }^{1} .{ }^{1}$ Department of Immunology and Rheumatology; ${ }^{2}$ Department of Radiological Sciences; ${ }^{3}$ Department of Public Health, Nagasaki University Graduate School of Biomedical Sciences; ${ }^{4}$ Clinical Research Center, Nagasaki University Hospital, Nagasaki, Japan

Background: We previously reported that the presence of autoantibodies, mag netic resonance imaging (MRI) bone oedema, ultrasound (US) power Dopple $(P D) \geqq$ grade 2 articular synovitis are indispensable markers to predict the development of RA from undifferentiated arthritis whereas combination analysis used by the above variables, focusing on very early phase of arthritis, remains to be done in our cohort.

Objectives: To investigate and re-confirm the diagnostic performance of autoantibodies, MRI findings and US findings toward early RA from NAGASAKI EARLY ARTHRITIS COHORT.

Methods: One hundred and three patients, suffering arthralgia less than 6 months and examined by both MRI and US of wrist and finger joints, were selected from NAGASAKI EARLY ARTHRITIS COHORT dating from September 2009 to August 2017. US were evaluated by synovitis score of semi-quantitative manner by gray-scale (GS) and power Doppler (PD) proposed from EULAR. In $\mathrm{MRI}$, synovitis, bone oedema and bone erosion were assessed by the Rheumatoid Arthritis Magnetic Resonance Imaging Scoring system (RAMRIS). After univariate analysis, multivariate analysis was employed to clarify the diagnostic predictors of early RA.

\begin{tabular}{|c|c|c|c|}
\hline & odds ratio & $95 \%$ confidence interval & $p$-value \\
\hline ACPA titer & 1.05 & $1.01-1.08$ & 0.0069 \\
\hline PD grade 2 & 17.43 & $5.15-59.06$ & 0.00025 \\
\hline
\end{tabular}

Results: Median of age was 60 years and that of symptomatic duration was 2 months. Female was $68.9 \%$, positive rate of RF was $64.7 \%$ and that of ACPA was $47.1 \%$. Total GS score was 4.0, total PD score 2.0, MRI synovitis score 3.0, MRI bone oedema score $0, \mathrm{MRI}$ bone erosion score 0 . Seventy patients were diag nosed as early RA during follow-up periods. A univariate analysis showed ACPA, CRP, MMP-3, fulfilment of 2010 ACR/EULAR criteria, MRI synovitis score, MR bone oedema score, total GS score, total PD score and PD $\geqq$ grade 2 articular synovitis were associated with early RA. Multivariate analysis revealed ACPA and $\mathrm{PD} \geqq$ grade 2 articular synovitis at any joints were independent predictors toward diagnosis of early RA 